\title{
La supuestamente ilegible escritura de médico como artefacto visual y estímulo creativo para la educación artística
}

\section{The Illegible Doctor's Writing as a Visual Artifact and Creative Stimulation for Art Education}

\author{
RICARD HUERTA \\ Facultad de Magisterio. Instituto de Creatividad e innovaciones Educativas. \\ Universidad de Valencia \\ ricard.huerta@uv.es
}

Recibido: 25 de abril de 2013

Aprobado: 9 de septiembre de 2013

\begin{abstract}
Resumen
El presente artículo analiza las posibilidades educativas de la particular escritura de los médicos, estudiando la componente gráfica de sus documentos, tanto históricos como recientes. Defendemos la escritura manual como un elemento gráfico importante para la educación artística, a partir de las premisas de la cultura visual. Nos basamos en los resultados positivos de la exposición "Caligrafías de la enfermedad. Letra de médico", una muestra en la que los visitantes son protagonistas, intérpretes y constructores de significados. Utilizamos la metodología de los estudios de caso, incorporando la observación directa de varios grupos de visitantes. También aportamos otros datos de la experiencia como el trabajo en equipo al plantear la actividad educativa o la participación de estudiantes universitarios en la elaboración de la exposición. Generamos un verdadero espacio colaborativo (Falk \& Dierking 2000) con la intención de promover experiencias de calidad para los diversos tipos de usuarios, de diferentes edades e intereses, de manera que entran en valor sus propias perspectivas y conocimientos. Hemos utilizado las a/r/tografías (Irwin \& O’Donoghue 2012) como referencia teórica válida para gestionar nuestras intenciones en la creación de los espacios. El discurso educativo recorre de este modo todo el conjunto de la exposición (Huerta, 2010).
\end{abstract}

Palabras clave: educación artística, museos, caligrafía, cultura visual, creatividad.

Huerta, Ricard. (2014): La supuestamente ilegible escritura de médico como artefacto visual y estímulo creativo para la educación artística. Arte, Individuo y Sociedad, 26(2) 317-336.

\begin{abstract}
In this paper we analyze the educational possibilities of medicine doctor's writing, studying graphic component of documents, both historical and the most recent. We defend handwriting as an important graphic element for art education, from the premises of visual culture. We analyze the positive results of the exhibition "Calligraphy of the disease, Medical Letter", in which are visitors actually actors, performers and builders of meanings. We use the methodology of the case studies, field work incorporating direct observation of several groups of visitors. We also provide the experience of teamwork when planning the educational activity involving university students in the preparation of the exhibition. We have generates a collaborative space (Falk \& Dierking 2000) promoting quality experiences for different types of users. We offer activities that can be used by visitors of different ages and interests, valuing their
\end{abstract}


own perspectives and knowledge. We used the a/r/tographies (Irwin \& O'Donoghue 2012) as theoretical references to manage our intentions to create the exhibition space and the educational space. Educational discourse runs throughout the entire exhibition, with a strong emphasis on public participation (Huerta, 2010).

Keywords: art education, museums, calligraphy, visual culture, creativity.

Huerta, R. (2014): The Illegible Doctor's Writing As A Visual Artifact And Creative Stimulation for Art Education. Arte, Individuo y Sociedad, 26(2) 317-336

La presente investigación forma parte del Proyecto I+D+i OEPE "Observatorio de Educación Patrimonial en España. Análisis integral del estado de la educación patrimonial en España”, con referencia: EDU2009-09679 (subprograma EDUC), y también de la actualización del proyecto "Educación Patrimonial en España: Consolidación, evaluación de programas e internacionalización del Observatorio de Educación Patrimonial en España (OEPE)" con referencia EDU2012-37212.

Sumario: 1. Preliminares, 2. Una exposición universitaria a partir de una anécdota popular, 3. Atracción por las letras dibujadas, 4. Una tradición muy europea que no acaba de arrancar aquí, 5. Una exposición repleta de letras, 6. Un espacio educativo generoso para este recorrido creativo y heterogéneo, 7. Metodología, 8. Un proyecto de cultura visual que recupera documentación médica e implica a educadores de museos, 9. La escritura manual se convierte en arte al ser reemplazada por el ordenador, 10. La exposición como un espacio educativo pendiente de los públicos, 11. Los usuarios también escriben, para exponer sus textos caligrafiaods, 12. La esencia educativa de la propuesta en sus diferentes versiones, 13. Diagnóstico final. Referencias.

\section{Preliminares}

De metges:

VII. Metges axi fisichs com cirurgians les receptes que dictaran hajen a dictar en romanç vulgar. E axi mateix hajen a declarar los noms del pes o mesura que.s declarant les noms de les herbes e de les altres coses medicinals en lur nom comú puxa clarament entendre per la gent popular. E qual-qui contra açó farà pach per pena cascuna vegada déu morababatins d'or dels quel's haja la cort la terça part e la terça la universitat del loch e la terça el acusador.

- Rey n'Amfos I (IV). Rúbrica XVII, cap.VII, pp. 209-210

Furs e ordinacions del Regne de València (edición L. Palmart de 1492)

Universitat de València, 1977

Presentamos al inicio de este artículo un texto medieval, que nos facilitan los historiadores Merche Gallent y Germán Navarro, en el cual queda patente un hecho que sigue vivo gracias a la tradición popular, a saber, que la letra de los médicos es ilegible. En el fragmento, perteneciente a los Fueros establecidos por el rey Alfonso I, leemos que se multará a los médicos y cirujanos que escriban incorrectamente o de manera ilegible sus textos, insistiendo en que puedan ser leídos perfectamente por la "gente popular", es decir, por el pueblo. En este pequeño fragmento encontramos otro de los misterios que rodean a la letra de los médicos: el posible interés de los doctores 
por salvaguardar las fórmulas magistrales de sus recetas. De estas cuestiones y de otros temas hablamos en el presente trabajo, ya que nuestro interés por la forma de las letras y sus expresiones gráficas nos llevó a promover una exposición sobre la letra de los facultativos, una muestra de carácter universitario que tiene como título genérico "Caligrafías de la enfermedad. Letra de médico".

\section{Una exposición universitaria a partir de una anécdota popular}

En noviembre de 2012 se presentaba en la Universidad de Valencia la exposición titulada "Caligrafías de la Enfermedad. Letra de médico" (del original "Cal-ligrafies de la malaltia. Lletra de metge"). La exposición forma parte de un proyecto más amplio en el que se aborda la temática de las letras de los médicos como auténticos documentos gráficos de la cultura visual. El proyecto expositivo se caracteriza por su componente educativa y de acción social (Rogoff 2008), por el carácter educativo que lo define, ya que por una parte utiliza como artefactos de la cultura visual los documentos escritos a mano por los médicos, y por otro lado introduce como engranaje la oferta participativa, promoviendo la interacción entre la organización y los diferentes públicos (Alderoqui, \& Pedersoli 2011).

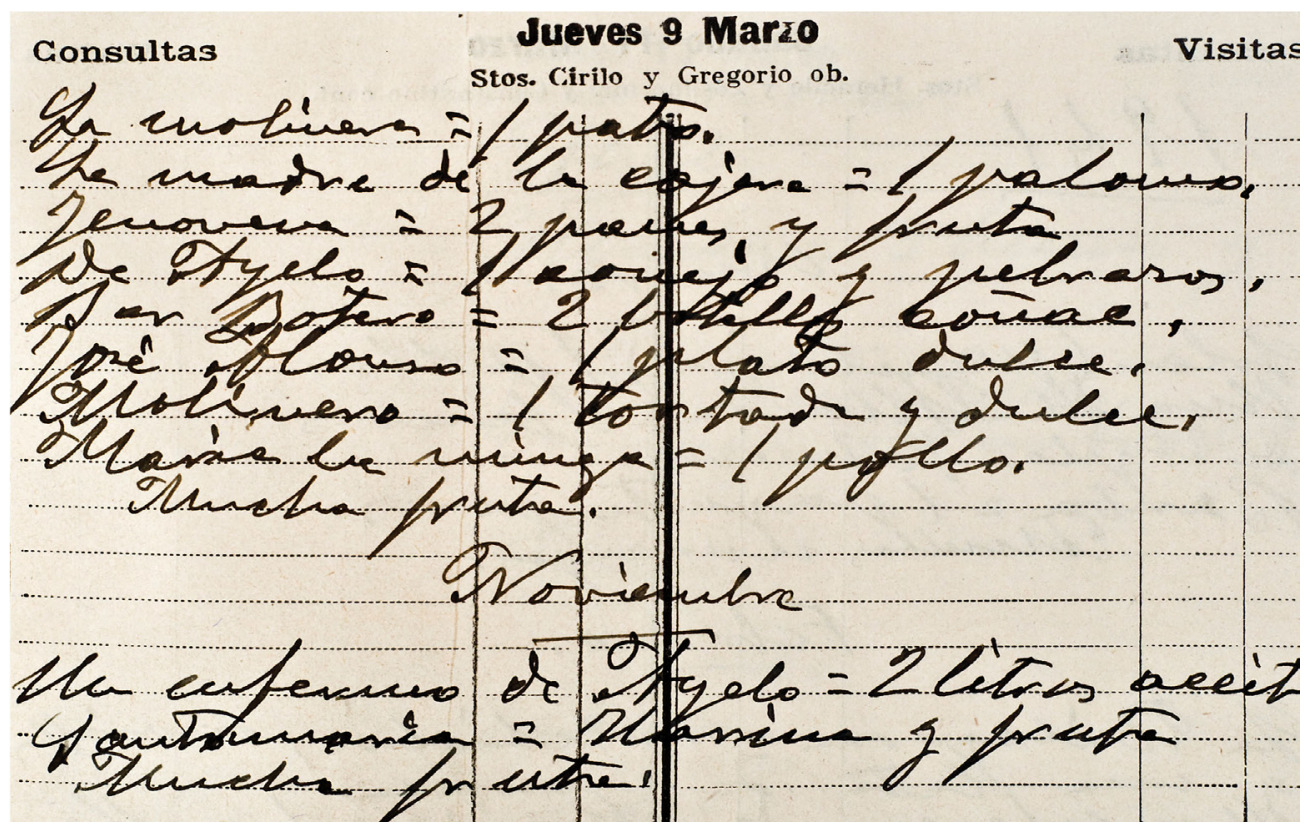

Figura 1. Documento escrito por un médico de Ontinyent en la posguerra (1940). Fotografía de: IHMC López Piñero

El proyecto universitario Caligrafías de la enfermedad reflexiona sobre el valor gráfico del texto manuscrito, dotando así de un valor estético a los documentos escritos a mano, obras que al mismo tiempo reflejan un conjunto de realidades de 
orden personal, social, cultural y científico. Caligrafías de la enfermedad revisa la escritura manual que realizan los médicos y analiza su aspecto compositivo desde la perspectiva de la cultura visual. La exposición ofrece la posibilidad de acercarnos a numerosos aspectos del lenguaje gráfico de la medicina que están íntimamente relacionados entre sí, como pueden ser la huella gráfica, el texto dibujado, la escritura, la tradición, e incluso los materiales y los instrumentos con los que se escribe y describe tanto la salud como la enfermedad. Al fusionar estos diferentes ámbitos podemos generar un novedoso espacio de mirada poliédrica, una nueva forma de observar los textos escritos manualmente. Teniendo en cuenta que en la actualidad se está generalizando el uso del texto procesado desde el teclado del ordenador, el presente proyecto revisa una tradición que ya tiene un cierto valor artístico y patrimonial, puesto que los textos manuscritos resultan cada día más escasos a nivel profesional, especialmente entre los escritos realizados por médicos.

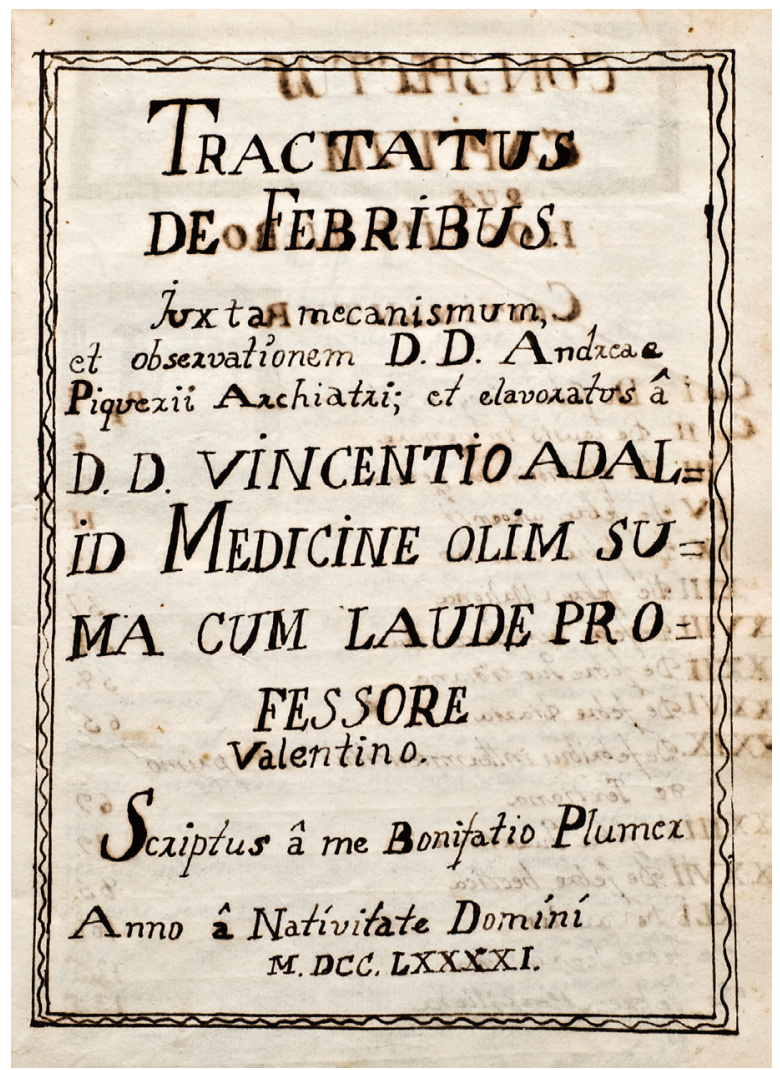

Figura 2. Primera hoja del "Tractatus de Febribus..." de 1791. Fotografía de: Biblioteca Universitat de València

La exposición se presentó inicialmente en el Palau de Cerveró, sede del Instituto de Historia de la Medicina y la Ciencia López Piñero de la Universitat de València, 
para seguir después con una itinerancia que la ha llevado a otras salas. La muestra ofrece la posibilidad de reflexionar sobre una serie de aspectos que nos planteamos a partir del interés que genera la escritura de los médicos, al tiempo que observamos las formas escritas que han definido el mundo de los facultativos. Recuperamos una tradición gráfica y también reivindicamos las escrituras y los textos como piezas de la cultura visual, como artefactos visuales realmente atractivos (Aguirre, 2004; Mirzoeff, 2006). Se trata de un proyecto innovador a nivel conceptual, al mismo tiempo que difunde documentos históricos de gran valor patrimonial, como son los textos escritos a mano por médicos e investigadores de la medicina que hemos podido rescatar de entre la documentación de nuestras bibliotecas históricas. Convertimos estos dibujos de letras y textos en auténticas piezas museables, teniendo en cuenta su valor histórico, científico, social, cultural y, muy especialmente, su potencial gráfico $\mathrm{y}$ visual.

\section{Atracción por las letras dibujadas}

Seguro que en alguna ocasión nos hemos quedado mirando la receta del médico intentando descifrar lo que allí había escrito. En ese momento nos planteamos por qué motivo resulta tan poco inteligible la letra de médico. Y entonces aparece nuestra curiosidad por averiguar por qué motivo los farmacéuticos entienden aquellos jeroglíficos dibujados por los médicos cuando recetan un medicamento o detallan la posología de una receta magistral. Cabe destacar sin embargo que entre los facultativos existe un buen número de especialistas que siempre se sintió muy atraído por la escritura. Resulta familiar la figura del médico que colecciona plumas, que se preocupa por la imagen gráfica de su consulta o clínica, que colecciona arte, que escribe con meticulosidad sus textos a mano, que tiene una caligrafía exquisita. Sin embargo, la idea general, la que ha calado a nivel común, es que los médicos escriben de forma ilegible, es decir, mal. Puede que en numerosos casos sea así, pero tampoco podemos olvidar otra realidad muy diferente, como es el hecho de que muchos médicos son auténticos calígrafos, personas que cuidan al máximo la imagen, y que se rodean de objetos valiosos como plumas estilográficas, escritorios, papeles elaborados a mano, o incluso sellos y sobres con los que acompañan su tarea manuscrita.

Caligrafías de la enfermedad nos introduce en el ámbito de la escritura de la medicina, en los textos escritos por los profesionales de la salud, articulando así un discurso liminar que aborda diferentes escenarios, e integrando en un mismo formato múltiples peculiaridades. Nuestra apuesta es por la innovación y la originalidad en los planteamientos. En nuestras Caligrafías se integran varios componentes atractivos que van desde la medicina, la escritura manual y las artes visuales hasta los diagnósticos, las recetas y la relación entre facultativos y farmacéuticos, provocando sinergias. $\mathrm{Al}$ mismo tiempo se redescubre la riqueza de la escritura en tanto que forma, en un momento histórico en el que la escritura manual ha sido desplazada por los teclados del ordenador y por otras tecnologías de la comunicación. 


\section{Una tradición muy europea que no acaba de arrancar aquí}

Tanto en Francia como en otros países europeos ha tenido gran difusión durante las últimas décadas un planteamiento expositivo para reforzar el papel de los textos como imágenes atractivas, una tendencia que no ha tenido excesiva repercusión en nuestra geografía peninsular. Un ejemplo de este interés europeo por los textos manuscritos sería la exposición Trésors de l'écrit. 10 ans d'enrichissement du patrimoine écrit, del año 1992, en cuyo catálogo, el entonces ministro de cultura Jack Lang escribía que Francia podía "sentirse orgullosa de poseer un patrimonio escrito particularmente rico y prestigioso". Lang defendía el ejercicio de políticas que valorasen el "enriquecimiento del patrimonio escrito". El siglo XX estuvo repleto de iniciativas en esta línea, entre las que destacaría los trabajos de Roland Barthes sobre la imagen de la escritura (Barthes, 1982), o los ensayos lingüísticos del Groupe Mju (1992). También nuestra universidad apostó por la belleza de la escritura manual en la exposición de 1990 L'art de l'escriptura, dedicada a los maestros calígrafos y basada en los trabajos del profesor Juan José Tornero. En aquella ocasión también se pretendía reivindicar la tradición que hasta 1970 hubo en la formación de maestros, ya que los planes de estudio de Magisterio incluían una asignatura anual llamada "Caligrafía" que era impartida por profesorado de Dibujo.

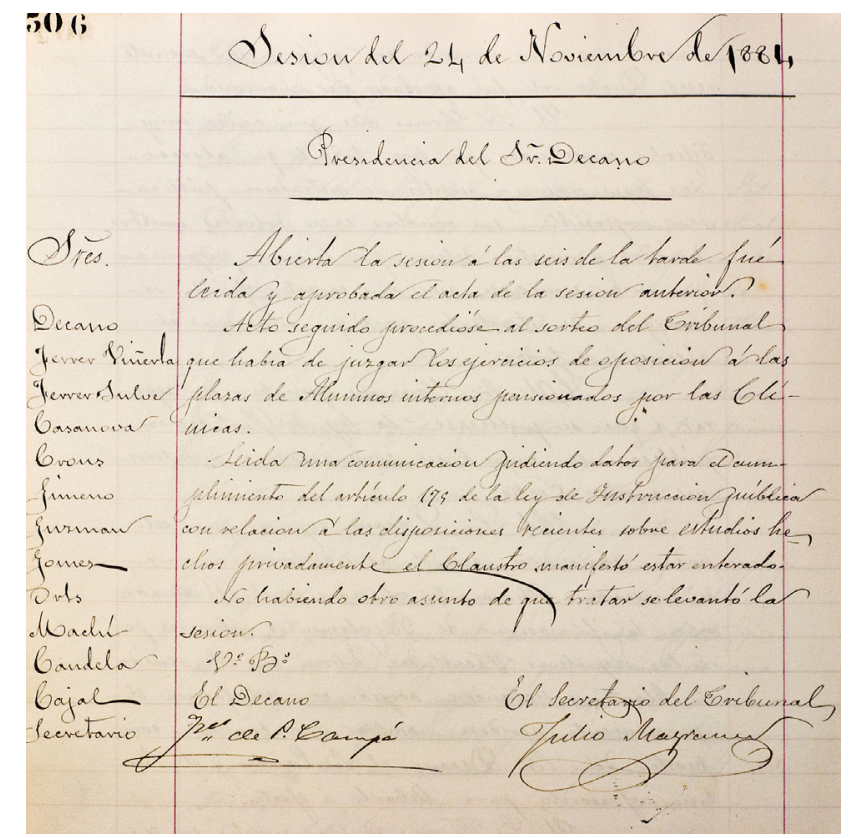

Figura 3. Acta de una reunión de la Facultad de Medicina con fecha del 24 de noviembre de 1884. Fotografía de: Universitat de València

Al realizar Caligrafías ha quedado comprobado el potencial gráfico de este tipo de documentación histórica, además de haberse descubierto un claro enlace con otros 
"géneros literarios" que han practicado los médicos y que pueden ser analizados desde la cultura visual: recetas, correspondencia, exámenes, actas de reuniones, informes, títulos, dietarios, y otras muchas "literaturas" particularmente afines al mundo de los médicos.

\section{Una exposición repleta de letras}

La exposición se distribuye en siete espacios conectados, además de un Espacio Educativo que ocupa más de la mitad del conjunto. Para cada uno de los siete apartados hemos contado con un especialista que favorece un encuentro peculiar con la letra manual o con los diagnósticos. Las temáticas abordadas en cada uno de los espacios permiten rastrear las posibilidades gráficas y culturales de una historia universitaria que nació en 1499 con la creación del Estudi General por parte de los jurados de la ciudad de Valencia.

\subsection{Médicos, escrituras y universidad. Grandes personalidades y rastro gráfico}

En el espacio 1 se presentan ejemplos del patrimonio que conserva nuestra universidad y que han sido seleccionados entre los fondos documentales de la Biblioteca Histórica y del Instituto de Historia de la Medicina y la Ciencia López Piñero. Se trata de documentos y textos escritos a mano por prestigiosos médicos a lo largo de la historia. Ofrece un itinerario que recorre varios siglos de tradición escrita, diseccionando la enjundia histórica del relato escrito que ha perdurado gracias a la huella gráfica ejecutada por los responsables de la salud, sin perder de vista las relaciones implícitas que conlleva un texto en el cual la enfermedad, la vida y evidentemente la muerte, constituyen factores ineludibles. Todavía no disponemos de un amplio catálogo en el que podamos recopilar los distintos géneros literarios que ha promovido el oficio de sanar. El universo de dichas letras está esperando la visión global de un astrofísico capaz de encauzar tantos signos diferentes en el firmamento del alfabeto.

\subsection{La extraña escritura de las enfermedades. La dificultad para leer la letra de médico}

El espacio 2 está dedicado a un texto del médico valenciano Vicent Sorribes, que pasó el verano del año 1943 como médico en el sanatorio de Fontilles. El libro Cuaderno de Fontilles. Un joven médico frente al fantasma de la lepra y la postguerra (Russafashow, 2008) relata dicha historia. Se necesitó la ayuda de un prestigioso paleógrafo para ayudar a descifrar el texto escrito, ya que resultaba muy complicado de leer. Erudición, imaginación y sabiduría fueron necesarias para llegar a penetrar en el jeroglífico que había que descifrar. El documento transcrito es una fuente de información que nos acerca a una realidad histórica, ya que desentraña una serie de conflictos personales y familiares, y además dibuja un relato vivido de los años cuarenta en una leprosería valenciana. Todo un acontecimiento, en forma y fondo, que ahora podemos revisitar. 


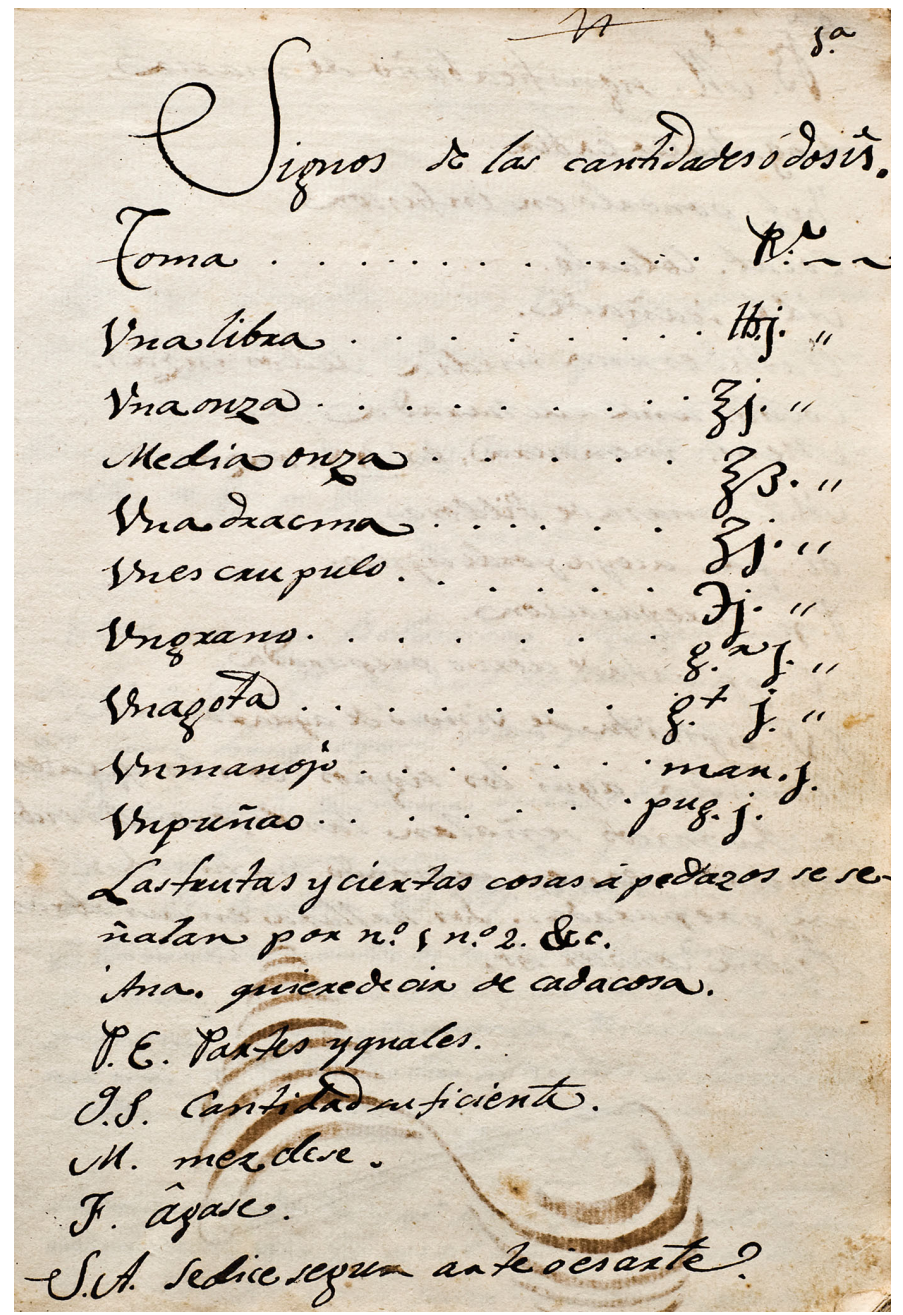

Figura 4. Acta Página del Formulario Quirúrgico o Ciencia de Medicamentos externos e internos precisos para curar las enfermedades de cirugía para el uso de Joaquín Navarro. Pasante en la Facultad, 1827.

Fotografía de: Biblioteca IHMC López Piñero. Universitat de València.

\subsection{Creación gráfica y sagas interdisciplinares}

En el espacio 3 se presentan los trabajos artísticos de Tana Capó, profesora de diseño en la EASD de Valencia, quien ha elaborado una serie de pinturas y collages a partir de los documentos escritos por su abuelo médico, coleccionista de plumas estilográficas, y hombre muy dado a organizar de forma milimétrica cada una de sus acciones cotidianas. 


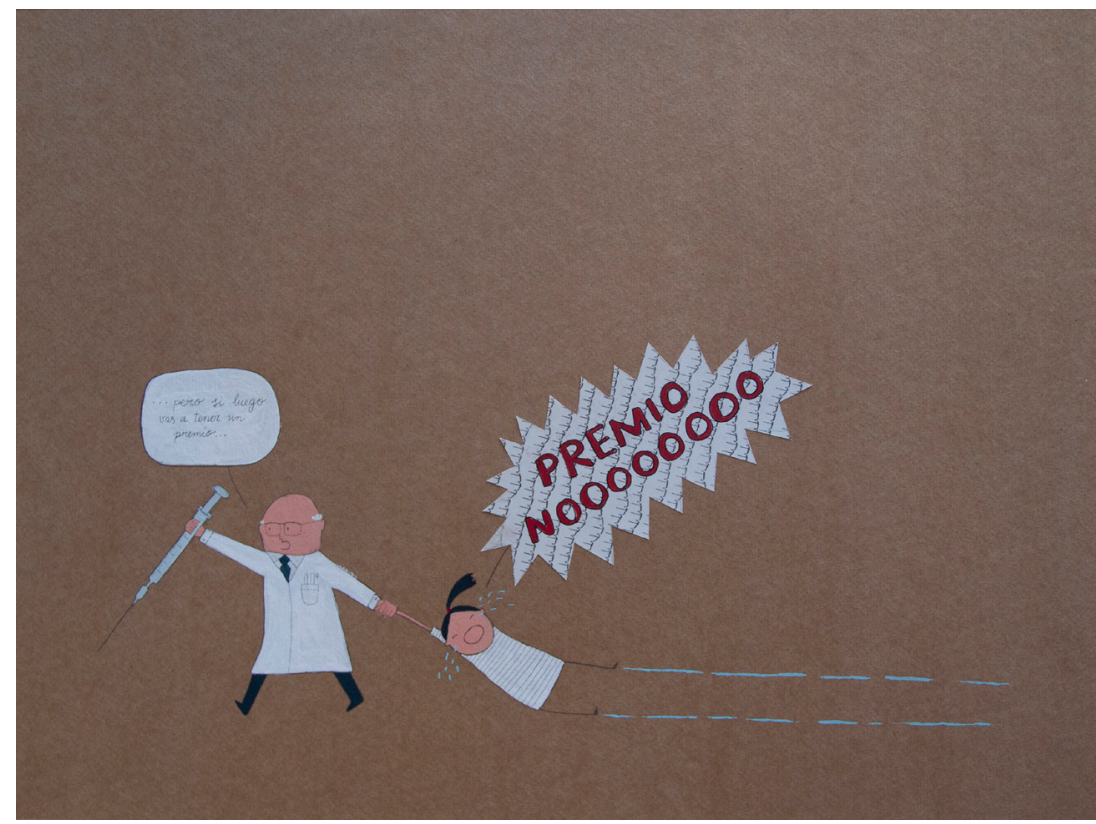

Figura 5. Ilustración de Tana Capó. Collage realizado con fragmentos de escritos de su abuelo médico.

Fotografía de: Tana Capó

Tana pertenece a una saga que integra médicos y artistas. Las juguetonas ilustraciones de la autora combinan a la perfección, cual fórmula magistral excepcionalmente conseguida, la relación entre nieta y abuelo, atendiendo a sus experiencias personales y recurriendo al legado gráfico que éste le proporcionó. El amor hacia su abuelo se define mediante una detallada enumeración de sus cualidades, representadas en los escritos y anotaciones que conservó. Tal y como lo describe la propia Tana, su abuelo "no fue hombre de memorias, sino de apuntes para evitar la desmemoria".

\subsection{Del médico de familia a la familia de médicos}

En el espacio 4 recorremos una saga familiar que inició Francisco Galiana y que se ha perpetuado durante tres generaciones de médicos de familia en Ontinyent. Abuelo, padre e hijo revisan, a través de su relato gráfico una tradición que ha velado por la salud de una población que es referente geográfico de la industria tradicional y punto neurálgico del espacio humano y geográfico de las comarcas centrales valencianas. Pudimos recorrer con Paco, nombre con el que familiarmente se le conoce, las calles melindrosas del recinto medieval de la Vila. Prácticamente todas las personas a quienes vimos saludaron a su médico con evidentes signos de aprecio. Incluso una mujer le recordó la situación dramática que supuso ver a su hijo cerca de una muerte casi segura, habiendo sido él quien detectó y diagnosticó la enfermedad. El cariño con el que la gente de Ontinyent saludaba a su médico de familia es un factor añadido al aprecio que se puede llegar a tener por un médico competente y experimentado. 


\subsection{El arte de la caligrafía china}

En el Espacio 5 sucumbimos a la evidencia de que la caligrafía china es un verdadero arte. A partir de la implicación del Instituto Confucio en este proyecto podemos acercarnos al potencial artístico y visual de las escrituras de los médicos orientales. La tradición oriental en el terreno de la medicina es muy diferente a la que conocemos en occidente. Más allá de la cura o de la atención a las enfermedades, la palabra escrita con las caligrafías chinas esboza un mundo muy arraigado a la geografía del cuerpo en relación con el entorno. La prevención, la atención personalizada del cuerpo, así como los usos de productos naturales -especialmente hierbas- han estado muy presentes en los métodos curativos de la medicina china. El arte de la caligrafía está presente en nuestra exposición como elemento identificativos de la cultura china y de sus transferencias gráficas.

\subsection{Comunicación entre profesionales, territorio no apto para profanos}

Dedicamos el espacio 6 a las relaciones entre comunicación, escritura, los profesionales de la salud y las enfermedades. El tránsito de información entre médicos y farmacéuticos represente un evidente mar de dudas. El ejercicio casi taquigráfico del médico recetando o proponiendo una posología puede llegar a herir ciertas susceptibilidades, especialmente cuando quien ha de descifrar aquellos barruntos se encuentra en una situación de desvalimiento, de riesgo evidente.

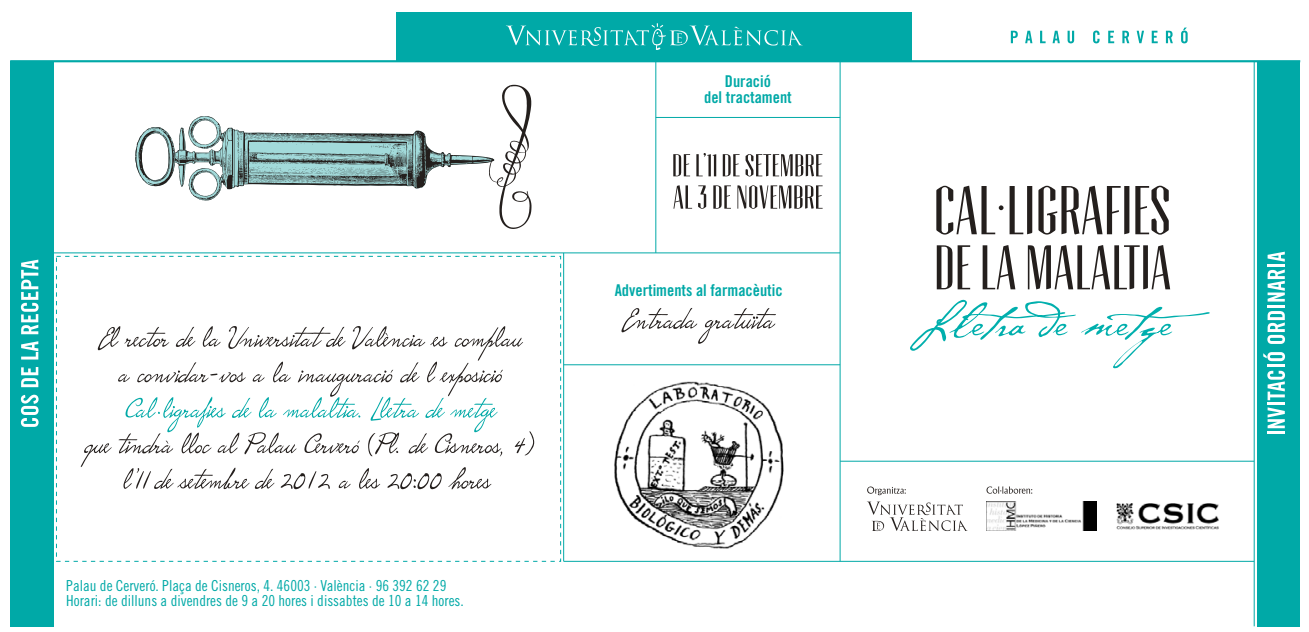

Figura 6. Invitación a la exposición con aspecto gráfico de receta médica. Diseño de: Ortogràfic

\subsection{Las otras caligrafias}

En el espacio 7 asistimos a una recreación de otros elementos que también "escriben" el relato de las enfermedades, como por ejemplo las radiografías, las ecografías, los electrocardiogramas y tantas otras nuevas formas de grafismo y de prescripción sonora que alimentan la distancia entre la persona sana y la que está enferma. Acorde con la ilegibilidad de los textos de los médicos, el oscurantismo a la 
hora de descifrar tales señales forma parte del nuevo régimen de ininteligibilidad que todos, excepto los profesionales de la sanidad, hemos asumido como un mal menor. Se trata de señales tecnológicas aptas para adentrarnos en los signos del diagnóstico y de ese modo ofrecernos un avance del mal del que vamos a morir. Las series de televisión ambientadas en hospitales que todos hemos seguido en alguna ocasión utilizan de forma exagerada este tipo de representaciones, caligrafías difíciles de entender si no es a través de la lectura propia del especialista.

\section{Un espacio educativo generoso para este recorrido creativo y heterogéneo}

La exposición Cal-ligrafies ha superado las cuatro mil visitas en sus dos primeras ubicaciones. Teniendo en cuenta que muchos de los visitantes son grupos de todas las edades y condiciones, desde escolares hasta asociaciones profesionales, hemos preparado para ellos un territorio de propuestas educativas y de interacción. Enfermos y apasionados del alfabeto podrán encontrar aquí una serie de propuestas para estimular sus deseos de conocimiento. Estos escenarios y las actividades programadas han sido generados por los estudiantes del diploma de posgrado Educación artística y gestión de museos, quienes han proyectado beneficiosas acciones, ambientadas algunas de ellas en una clínica de médico. Se anima a los visitantes a vestirse de médico y fotografiarse, al mismo tiempo que escriben una receta. Estas recetas se distribuyen en los muros del espacio educativo, para que puedan leerse por el resto de usuarios. Se han elaborado materiales educativos para las diferentes edades de los visitantes: escolares de educación infantil y primaria, alumnado de secundaria, mayores, familias, y grupos.

Además de las propuestas del espacio educativo se ofrecen actividades relacionadas con la temática, como un ciclo de películas, una serie de acciones artísticas, y también conferencias y mesas redondas que completarán nuevas miradas hacia la escritura de los médicos. Y todo ello bajo la mirada atenta del diseño creado por el equipo de Ortogràfic, quienes han captado con sus creaciones la esencia de nuestros padecimientos. El comisariado de la exposición, que ahora más que nunca definiría como curadoría de la misma, suponía implicar a muchas personas en el proyecto, con un espíritu de cooperación y de apoyo constante, el peculiar engranaje que ha transitado por todos los dominios de esta iniciativa.

Analizamos seguidamente cada una de las novedades que ha ofrecido esta innovadora experiencia, destacando su gestación, los logros educativos, las aportaciones en materia de cultura visual, e incluso el impacto mediático que ha tenido la propuesta. Se tienen en cuenta todas las aportaciones e informaciones que nos han llegado desde cada colectivo que ha participado en la experiencia. Que no te duela; intenta descifrarla. 


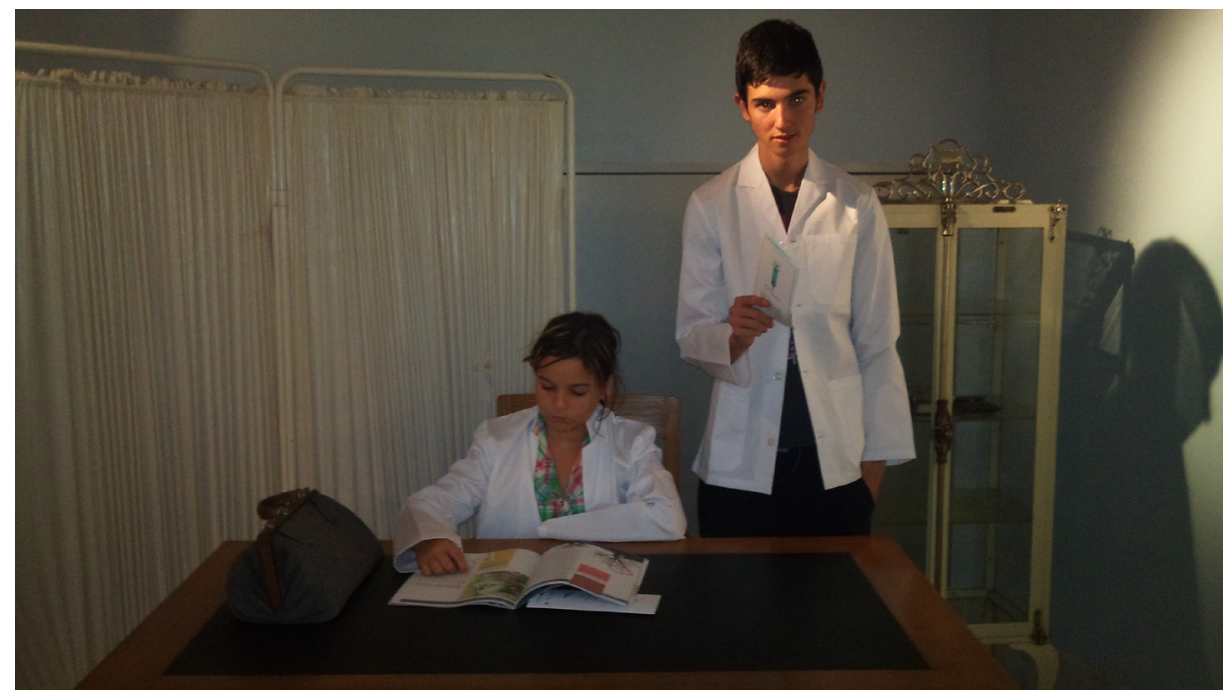

Figura 7. Dos jóvenes visitantes de la exposición se visten con el atuendo de médico y escriben su receta "para salir de la crisis". Fotografía de: Ricard Huerta

\section{Metodología}

Hemos realizado una investigación de corte cualitativo. Se trata de un estudio de caso en el que se analiza tanto la gestación de las ideas como la producción de la exposición a partir de las acciones coordinadas de todos los implicados en el proceso. Se indaga en las diferentes fases del proyecto, observando su evolución y la actuación de los participantes. Ha predominado la observación directa y se han realizado entrevistas semi-estructuradas con el personal que colaboró en la producción de la exposición y en la realización de los talleres educativos. Para la investigación hemos contado con un número significativo de personas que cubren diferentes ámbitos: alumnado becario y en prácticas, coordinadores de sala, responsables de comunicación institucional, gestores administrativos, asesores técnicos y voluntarios. Se han valorado las relaciones corporativas y los intereses de cada colectivo. Esta composición variada de los informantes permitió aportaciones en varias direcciones, lo cual nos ha dado elementos de contraste y verificación sobre los ejemplos suministrados. Con el consentimiento de los participantes se realizaron filmaciones, grabaciones en audio y notas de campo. Se ha recopilado y analizado gran parte del material producido para la exposición.

El comisariado de la exposición cumple con los requisitos que se recogen en las teorías y prácticas $\mathrm{a} / \mathrm{r} /$ tográfícas, con un discurso impulsado por el equilibrio entre la acción artística y la propia experiencia docente. Interaccionamos desde nuestra posición de profesores de educación artística con el alumnado de educación en museos, tal y como sugieren Irwin \& O’Donoghue (2012).

Para valorar la recepción del proyecto por parte del público hemos entrevistado a visitantes y se han recogido los resultados de las actividades realizadas por los participantes durante las sesiones. También se han estudiado las respuestas de los 
grupos de jóvenes y adultos convocados a las visitas guiadas. Comprobamos que nuestro concepto expositivo encarna en su práctica la esencia del denominado giro educativo desde una perspectiva crítica de la mediación. Contemplamos el planteamiento de Irit Rogoff (2008) al establecer nuevos criterios emergentes en relación con el comisariado de exposiciones. Hemos incidido en un modelo educativo de corte crítico, acentuando el interés por la pedagogía activa (Alderoqui y Pedersoli, 2011; Huerta, 2010). Se evidencia así una postura socio-crítica que le da identidad, replanteando la función social de las exposiciones. De este modo conseguimos que el objetivo institucional se vaya desplazando desde la mera conservación del patrimonio hacia la atención al visitante. La gestación de la exposición tuvo un proceso marcado por la participación de los colaboradores, y los resultados avalan la implicación de los visitantes. En la preparación y el desarrollo de la exposición participó activamente el alumnado del diploma universitario "Educación Artística y Gestión de Museos", un curso que ha propiciado recientemente la creación de la "Asociación Valenciana de Educadores en Museos (AVALEM)".

\section{Un proyecto de cultura visual que recupera documentación médica e implica a educadores de museos}

Nuestro proyecto está orientado hacia la multiplicación de imaginarios colectivos, activando el dominio de lo público. Presentamos la escritura manual como un verdadero ámbito artístico, como un medio para promover reflexiones, para educar a la comunidad y para poner en circulación documentos que perdieron su valor como contenido científico pero que mantienen un gran valor artístico. El arte incita a la resignificación individual y social. Los resultados clarifican enormemente numerosos aspectos sobre la acción educativa de las actuales exposiciones, al combinar una temática interdisciplinar con un proyecto educativo que ha disfrutado de gran reconocimiento tanto por parte del público como de los medios de comunicación. La exposición genera una propuesta eminentemente educativa, al ofrecer un conjunto de actividades que permiten aproximar el conocimiento y la cultura al público, de manera que se contribuye a la formación de los ciudadanos en lo estético y en el arte, sin dejar de incluir en ello una propuesta de lectura crítica de la historia y del contexto, activando al mismo tiempo los factores propios de la identidad (Falk, 2008). Al tratarse de textos escritos por médicos, se interrelacionan los dos ámbitos más importantes de los servicios de atención pública: la educación y la sanidad.

La apuesta educativa es la formación de los sujetos, centrada en el visitante, lo cual conlleva una mentalidad educativa y formativa en sentido amplio, propiciando el desarrollo de la percepción, la imaginación y la creatividad. Se persigue una experiencia estética, generando en los sujetos sensibilidad, preguntas y reflexiones fundamentales frente a sí mismos, a su sociedad y a la vida. Se fomenta el conocimiento de las colecciones, apropiándose de sus valores gráficos. Con esta actividad concedemos un valor añadido a la colección de manuscritos escritos por médicos durante más de cinco siglos en la Universitat de València.

El proyecto expositivo estuvo desde el inicio relacionado con el diploma de 
posgrado "Educación artística y gestión de museos", un curso universitario en el que se prepara a educadores de museos. El alumnado del diploma realiza prácticas externas en los museos. En la edición de 2012 les ofrecimos además la posibilidad de formar parte del staff de la exposición "Caligrafías de la Enfermedad". Todo el alumnado quiso participar voluntariamente en la experiencia. Lo que les ofrecemos es la posibilidad de participar en la elaboración de un proyecto expositivo desde sus inicios, de manera que no son únicamente los responsables de las actividades educativas, sino que participan activamente en todo el montaje.

\section{La escritura manual se convierte en arte al ser reemplazada por el ordenador}

Teniendo en cuenta que en la actualidad se está generalizando el uso del texto procesado por ordenador, el proyecto evidencia la tradición de la caligrafía, que adquiere un mayor valor histórico, artístico y patrimonial. Revisamos la escritura manual que realizan los médicos y analizamos su aspecto compositivo desde la perspectiva de la cultura visual. La exposición ofrece la posibilidad de acercarnos a numerosos aspectos del lenguaje gráfico de la medicina que están íntimamente relacionados entre sí, como la huella gráfica, el texto dibujado, la escritura, o los materiales y los instrumentos con los que se escribe. Recuperamos una tradición gráfica y también reivindicamos las escrituras y los textos como piezas de la cultura visual, como artefactos visuales atractivos y significativos (Hernández 2000). Damos a conocer documentos que fueron escritos por médicos en momentos concretos de la historia y que ahora tienen un valor añadido como imágenes que fueron dibujadas en una determinada coyuntura social y estética. Por este motivo se trata de un proyecto innovador como concepto, ya que al mismo tiempo que difunde documentos históricos de gran valor patrimonial, rescata de nuestra biblioteca histórica los textos escritos a mano por médicos e investigadores de la medicina.

\section{La exposición como un espacio educativo pendiente de los públicos}

La actividad educativa modula esta exposición sobre las caligrafías de los médicos. Planteamos un itinerario por los logros históricos de la medicina, combinando de forma atractiva imágenes e ideas. A las personas y grupos de usuarios les ofrecemos un recorrido creativo y heterogéneo por la tradición de la letra de médico, un ámbito poco tratado anteriormente. Se anima al visitante a examinar estos documentos, fuente de inspiración sobre cuestiones que tanto nos afectan como la salud o la enfermedad. 


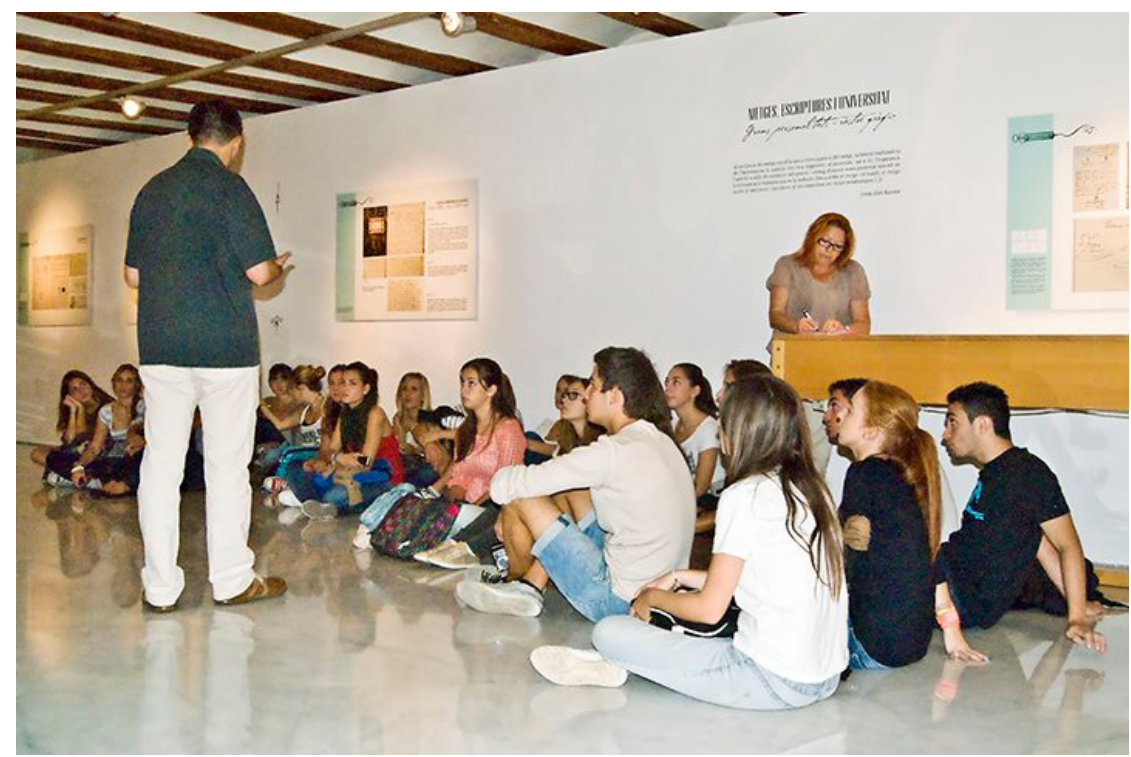

Figura 8. Grupo de alumnado universitario visitando la exposición. Fotografía de: IHMC López Piñero

El itinerario incluye un importante espacio de acción educativa en el que incorporamos juegos para el alumnado escolar y planteamos reflexiones para el resto de públicos.

La actividad del mural en el que se insertan mensajes en forma de receta anima a cada visitante a aliviar los males del mundo (Duncum, 2008). Todas las recetas pasan a formar parte del mural en el que se pueden leer las ideas que han escrito los sucesivos participantes. Se imprimió un talonario de recetas similar a las que usan los médicos en la consulta. El texto que escribía cada persona que visitaba la exposición podía consistir en una propuesta para mejorar el mundo, o bien en una idea para curar los males que nos afectan de forma cotidiana.

\section{Los usuarios también escriben para exponer sus textos caligrafiados}

Las ideas recogidas en las recetas que escribieron los asistentes son muy variadas. Nos parece muy positiva la apuesta de la mayoría de los visitantes al implicarse en deseos que reflejan valores necesarios como la solidaridad, el respeto o la integración: "Cultura y educación para toda la vida", "Apoyar a los colegios públicos", "Que toda la sociedad tenga las mismas oportunidades de estudios y trabajo". Algunas de las intervenciones escritas se refieren a la preocupación por la actual situación de crisis económica y por las políticas basadas en los recortes sociales: "Necesitamos mejores condiciones para la enseñanza pública", "Que no se recorte el dinero para la investigación", "Me preocupan los recortes en sanidad y educación". En algunos casos el texto ha sido escrito por un niño de corta edad, preocupado por sus problemas más inmediatos y cotidianos: "Me duele la garganta porque me ha pegado el constipado 
Javier". La abundancia de esta tipología de mensajes está directamente relacionada con la gran afluencia de grupos escolares. En algunas respuestas incluso se reclaman actividades, siempre agradeciendo la labor de los educadores: "Quiero más talleres como este", "Gracias por rescatar la memoria de las personas que trabajan por amor a la profesión".

Cabe decir que resulta complicado leer algunos de los textos escritos a mano por los visitantes debido a su extraña caligrafía. Pero no podemos perder de vista que, al tratarse de sus textos manuscritos, y al estar muy visibles en el muro de la exposición como si se tratase de un panel, los nuevos públicos también pueden ver en cada receta, además del comentario escrito, la caligrafía de la persona que lo había realizado. Con ello se cumple uno de los objetivos de la muestra: dar tanta importancia a la forma del texto escrito como al contenido del texto.

Cada visitante interviene de diversas formas, ya que los dispositivos participativos invitan a la conversación en pequeños grupos, planteando preguntas. Desde la concepción y diseño del proyecto asumimos la responsabilidad de promover acciones educativas y culturales reivindicando la memoria colectiva. La visita a la exposición se convierte en un acontecimiento social de creación y disfrute, en un elemento de transferencia generacional.

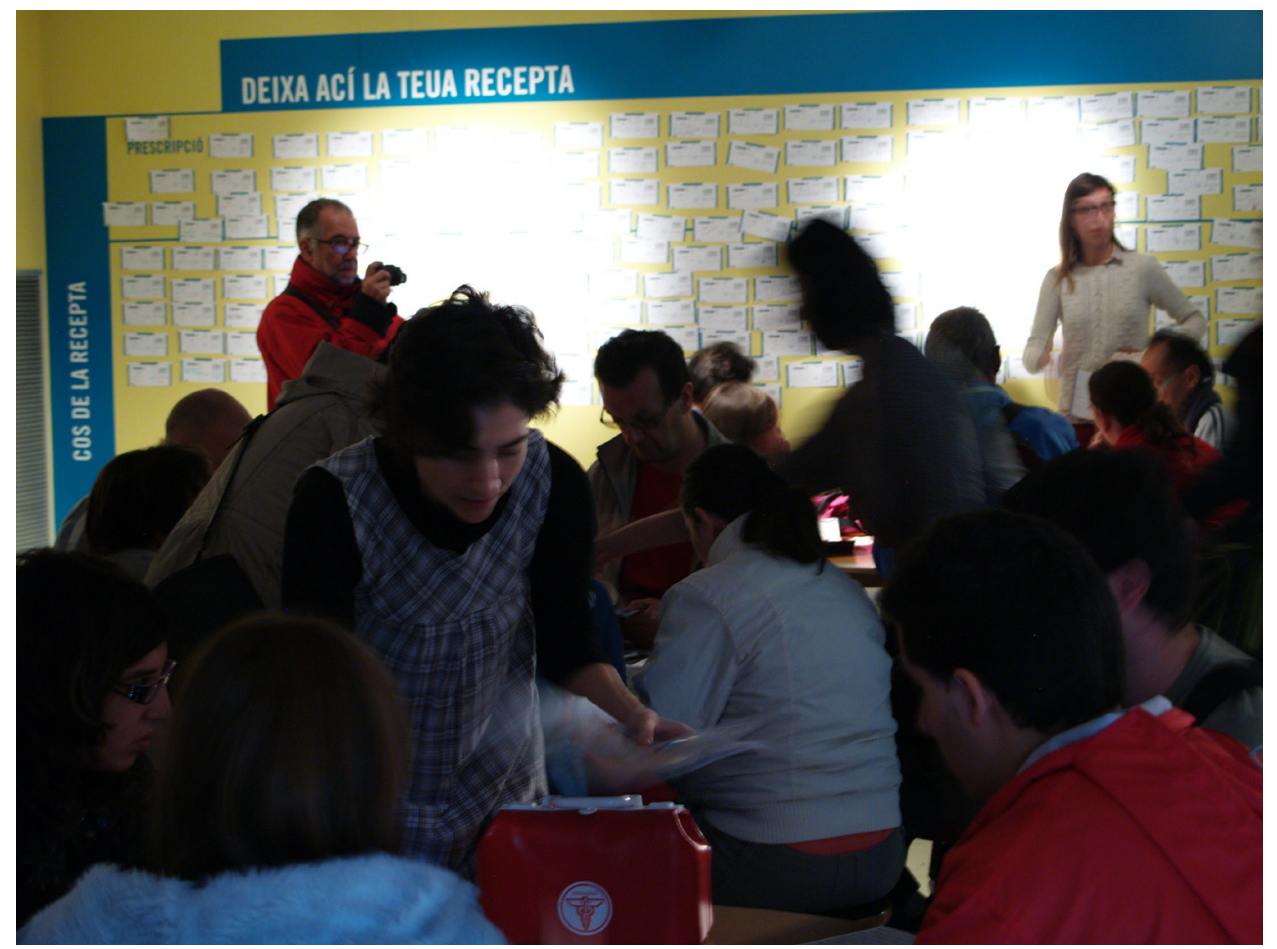

Figura 9. Grupo de educación especial realizando una actividad. Al fondo vemos el mural con las recetas escritas. Fotografía de: Ricard Huerta 
Los visitantes se convierten también en creadores de la exposición, en base a prácticas transformadoras, propias del denominado giro educativo que caracteriza los proyectos contemporáneos. En la preparación y la realización de los talleres participan representantes de todas las áreas de la institución, lo cual permite desvelar las percepciones e imaginarios que cada uno de ellos tiene sobre la naturaleza educativa y cultural de la exposición. Se centraliza la función educativa del proyecto, tal y como sugiere el enfoque de Anderson (2004) cuando apunta hacia los aspectos organizativos, abogando por un intercambio entre los trabajos de curaduría y educación, centrando las prioridades en el conocimiento de las audiencias y promoviendo un estilo comunicacional de diálogo y reconocimiento del visitante. Es el sujeto quien decide dónde, cómo, con quién, cuándo y qué quiere aprender. Se trata de un aprendizaje por Libre Elección (Free-Choice Learning) para indicar el que sucede a lo largo de la vida (Falk y Dierking, 2000). Estos aprendizajes son más duraderos y significativos para los individuos puesto que son el resultado de los intereses y expectativas del sujeto.

\section{La esencia educativa de la propuesta en sus diferentes versiones}

La vertiente educativa de la exposición ha sido un elemento clave desde el inicio de la gestación del proyecto. Preguntamos a las responsables de las actividades educativas si consideran importante iniciar su trabajo al mismo tiempo que se está desarrollando la producción de la exposición. Las 15 educadoras implicadas dicen que "no solamente es importante, sino que es fundamental", y añaden que "una exposición se concibe con el principal objetivo de difundir contenidos culturales, y en este sentido es un espacio educativo". Al preguntarles sobre los aspectos que les preocupaban cuando se estaba gestando la exposición nos dicen que lo que más deseaban era una "buena y constante comunicación entre el comisario, la coordinadora de exposiciones y las educadoras, para llegar a un acuerdo coherente con el trabajo de las tres partes". También les preocupaba "la necesidad de adaptar las actividades educativas en función de cada público, atendiendo a sus necesidades". Les preocupaba "que se entendiera lo que querían transmitir, para que los visitantes se fueran contentos con un aprendizaje importante tras haber desarrollado los talleres". Explican que las reuniones con la coordinadora técnica ayudaron a clarificar muchas cuestiones.

Entre el alumnado de secundaria funcionó muy bien una práctica basada en el juego de imágenes que conectaba los textos de los documentos expuestos y las fotografías recortadas de revistas de medicina. El alumnado diseñaba sus propias composiciones con la técnica del collage, imbricando texto e imagen, lo cual nos remite a la reflexión de Anacleto Ferrer (2013, 229): "Definitivamente, la vida cotidiana en la modernidad nos obliga a leer textos y mirar imágenes en combinación los unos con las otras". Las temáticas que observamos en los trabajos del alumnado adolescente están muy vinculadas a sus propios intereses, especialmente en relación con la identidad y la imagen individual.

Por su parte, el alumnado de primaria confeccionaba un cuerpo humano con arcilla moldeable, incorporándolo a un desplegable en el que aparecían detalladas las 
características de cada órgano. Esta actividad servía posteriormente a los maestros para explicar cuestiones de salud y de ciencias naturales.

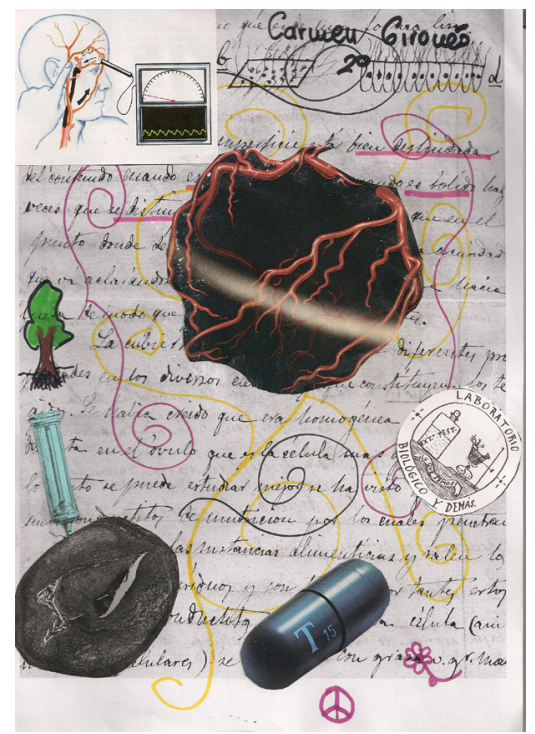

Figura 10. Collage realizado por una alumna del Instituto de Secundaria la Misericordia. Collage de Carmen Gironés

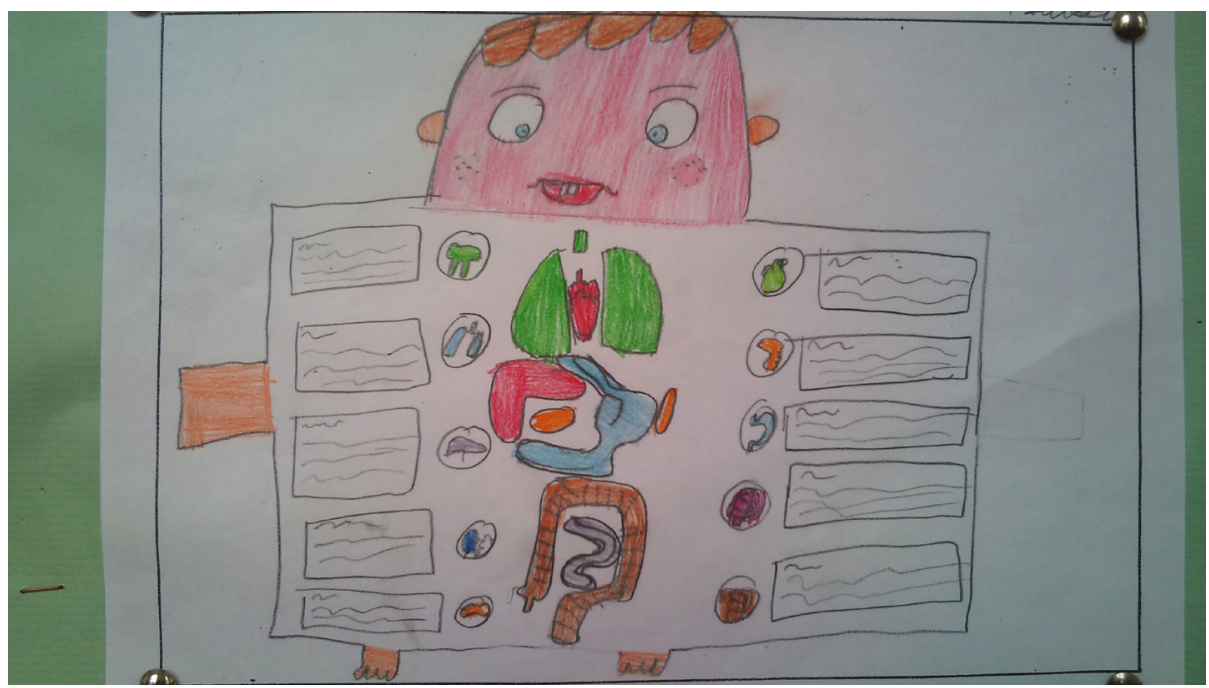

Figura 11. La actividad pensada para primaria consistía en elaborar un cuerpo humano con sus diferentes órganos. Trabajos del Colegio Cervantes de Valencia. Fotografía de: Ricard Huerta 


\section{Diagnóstico final}

Con la presente investigación hemos demostrado que una exposición puede funcionar de manera más homogénea si se abordan los aspectos educativos desde el inicio del proyecto, combinando creatividad, originalidad y riesgo. A partir de los parámetros que combinan la educación artística y la cultura visual desarrollamos experiencias intergeneracionales, desarrollando una metodología de conversación curatorial. Esta modalidad de trabajo política, ética y poética a la vez (Duncum, 2008) es parte de un modelo de formación y capacitación continua en el marco de un proyecto que va creciendo sobre los procesos creativos. Consideramos crucial el papel de los visitantes como eje que articula sus experiencias, sus propios relatos y sus reivindicaciones. La escritura se convierte en elemento de convergencia al proyectarse una mirada artística hacia la caligrafía. Hemos conseguido contagiar de entusiasmo a los públicos asistentes, animándoles a participar activamente en la propuesta. El presupuesto ajustado se ha compensado con el aliciente de las nuevas interpretaciones, ya que la muestra se nutre del material que posee la universidad, aprovechando de forma eficiente su riqueza documental y gráfica. Conviene por tanto favorecer el engranaje educativo de cada exposición, olvidando los presupuestos millonarios que se barajaban en los años anteriores, para potenciar la educación en valores y el goce de las situaciones sociales de intercambio entre todas las personas con intereses culturales y democráticos.

\section{Referencias}

Aguirre, I. (2004). Beyond the Understanding of Visual Culture: A Pragmatist Approach to Aesthetic Education. International Journal of Art \& Design Education, Vol. 23, No. 3, pp. 256-269.

Alderoqui, S. \& C. Pedersoli (2011). La educación en los museos. De los objetos a los visitantes. Buenos Aires: Paidós.

Anderson, G. (2004). Reinventing the Museum, Historical and Contemporary Perspectives on the Paradigm Shift. Walnut Creek, California: AltaMira Press Barthes, R. (1982). L'obvie et l'obtus. Essais critiques III. Paris: Editions du Seuil.

Duncum, P. (2008). Holding Aesthetics and Ideology in Tension. Studies in Art Education, Vol. 49, No. 2, 122-135.

Falk, J. H. (2008). Viewing Art Museum Visitors Through the Lens of Identity, Visual Arts Research, Vol. 34, No. 2, pp. 25-34.

Falk, J. H. \& Dierking, L. D. (2000). Learning from museums: Visitor experiences and the making of meaning. Walnut Creek, California: Alta Mira Press.

Ferrer, A. (2013). Intertextos, Archivo de Arte Valenciano, No. 93, pp. 215-234.

Groupe Mju (1992). Traité du signe visual. Pour une rhétorique de l'image. Paris: Editions du Seuil.

Hernández, F. (2000). Educación y cultura visual. Barcelona: Octaedro. Huerta, R. (2010). Maestros y museos. Valencia: PUV. 
Irwin, R. \& O'Donoghue, D. (2012). Encountering Pedagogy trough Relational Art Practices. International Journal of Art \& Design Education, Vol. 31, No. 3, pp. 221-236.

Mirzoeff, N. (2006). On Visuality, Journal of Visual Culture, Vol. 5, No. 1, pp. 5379.

Rogoff, I. (2008).Turning, E-flux journal, No. 0 (online) Available at:

http://www.e-flux.com/journal/turning/ (accessed 4 March 2013) 